\title{
Decarbonizing the UK energy system and the implications for UK shipping
}
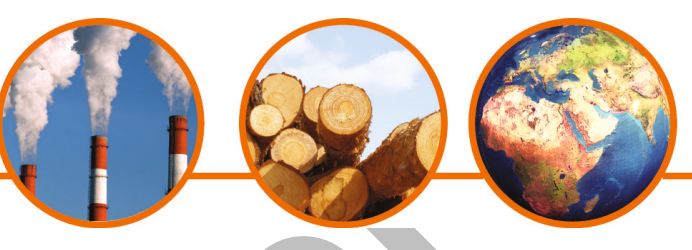

Sarah Mander ${ }^{* 1}$, Conor Walsh', Paul Gilbert ${ }^{1}$, Michael Traut ${ }^{1}$ \& Alice Bows ${ }^{1,2}$

Background: The current UK energy system relies heavily on shipped imports of fossil fuels. As climate change policies drive energy system decarbonization, fuel imports are likely to change. Results: Based upon future energy scenarios devised by the UK's Department of Energy and Climate Change and a set of contrasting trading assumptions, this article explores the impact of energy system decarbonization upon freight work and $\mathrm{CO}_{2}$ emissions arising from fuel shipping. While oil and oil products are currently the most important contributors to both freight work and shipping $\mathrm{CO}_{2}$ emissions, by 2050 biofuels and biomass will become dominant energy commodities. Conclusion: The distance over which fuel travels is important and the greatest reductions in absolute $\mathrm{CO}_{2}$ emissions are achieved when fuel is sourced close to the UK.

In 2008, the UK adopted a policy of reducing GHG emissions by $80 \%$ by 2050 , within specified emissions budgets, and instigated policies with the aim of achieving this challenging objective $[1,2]$. Coupled with reducing energy demand, meeting this target requires the deployment of low-carbon technology across the whole energy system for the provision of heat, electricity and energy for transport, as a transition is made from a carbon-intensive energy supply system to one that is largely decarbonized. The emissions from international shipping, along with those from international aviation, were not included within the current emission reduction target and emissions budgets, and there is inherent uncertainty in the precise level of their future emissions $[3,4]$. This exclusion is to be reviewed towards the end of 2012, with the UK Government's independent advisor on climate change, the Committee on Climate Change (CCC), recommending that these emissions be brought within the UK climate change mitigation policy framework [5]. Under an emission budget, all sectors of the economy have to contribute to reductions so that national emissions remain within the budget. If one sector does less, or is less able to reduce its emissions, other sectors must make larger reductions.
Thus, inclusion of the $\mathrm{CO}_{2}$ emissions from international transport into the 2050 target would place greater pressure on other sectors of the economy to reduce their emissions while at the same time necessitating $\mathrm{CO}_{2}$ reductions from international shipping and aviation.

In light of the potential inclusion of shipping $\mathrm{CO}_{2}$ emissions within the UK's climate change targets, it is worthwhile to reflect on an appropriate emission boundary for UK shipping. The issue of apportioning international shipping emissions to regions or nations has been the focus of debate since the 1990s, when the UNFCCC's Subsidiary body for Scientific and Technological Advice outlined a range of apportionment regimes as a step towards allocating and controlling emissions [6,7]. However, this has been contested, with many in the sector supporting the treatment of shipping as a nation, tackling it through the International Maritime Organisation (IMO) rather than national or regional policy measures $[4,8,9]$. Nonetheless, with regions and nations wishing to estimate their emissions for the purposes of carbon budgets and targets [10] and as a means to monitor policy at a subglobal scale [11] there has been considerable debate surrounding how to apportion emissions and what constitutes regional or national

Tyndall Centre for Climate Change Research, School of Mechanical, Aerospace \& Civil Engineering, University of Manchester, M13 9PL, UK

${ }^{2}$ Sustainable Consumption Institute, School of Mechanical, Aerospace \& Civil Engineering, University of Manchester, UK

*Author for correspondence: E-mail: s.mander@manchester.ac.uk 


\section{Key terms}

Emission budget: Quantity of emissions that a country or sector is allowed to emit over a specified period.

Energy efficiency design index: Tool proposed by the International Maritime Organisation for establishing an emission benchmark for new ships.

Freight work: Quantity of freight transported multiplied by the distance traveled.

Carbon intensity: Carbon emissions associated with a given unit of activity.

Emission factor: Emission rate of a given GHG for a given source, relative to units of activity. shipping [10,12-19]. This article takes the position argued by the CCC and Gilbert et al., that any regional or national shipping emissions estimate be based on the goods imported and/or exported to the UK [10]. On this basis, current UK shipping emissions are of the order of 12-16 $\mathrm{Mt} \mathrm{CO}_{2}$ [13]. This is some $2 \%$ of UK emissions, when calculated by bunker fuel sales, though this approach is likely to underestimate shipping $\mathrm{CO}_{2}$ emissions [20].

To tackle the $\mathrm{CO}_{2}$ emissions from shipping, the IMO has mandated an energy efficiency design index (EEDI) and a Ship Energy Efficiency Management Plan that will come into force from the start of 2013 and will apply to all new ships of 400 gross tonnes and above. While the IMO considers that these policies will enable the sector to fulfil its obligations to contribute to meeting international commitments on climate change, Anderson and Bows demonstrate that these policies do not go far enough towards reducing the absolute $\mathrm{CO}_{2}$ emissions from shipping [8]. Against this backdrop, it is useful to consider how $\mathrm{CO}_{2}$ emissions from shipping may change, not as a result of technical or operational measures, but as a result of changing demand for shipping services. While the shipping market is highly complex and dynamic with competition between shippers and ports, the shipping sector is strongly influenced by other sectors in terms of demand for its services [21,22]. Therefore, changing demand for goods and the consequent demand for shipping reflects the state of the economy, changing tastes and broader structural changes. One such impending structural change is the decarbonization of the UK energy system, which is, at the moment, predominately fossil fuel based and heavily reliant on imports arriving in the UK by ship [23]. The future energy system required to meet the climate change targets may take many different forms, and different energy supply options will have a knock-on effect on the patterns of fossil fuel trade into and out of the UK, with a corresponding impact on the demand for shipping and its emissions.

This article uses the case of decarbonization of the UK energy system to explore how demand for fuels and the demand for the shipping of that fuel impacts on the resulting $\mathrm{CO}_{2}$ emissions. A scenario framework, previously applied to the whole UK energy system has been adapted and applied, for the first time, to the UK shipping sector to focus on fuel imports [24]. In so doing, the paper: estimates current $\mathrm{CO}_{2}$ emissions from the import of fuels into the UK; considers the implications of Department of Energy and Climate Change (DECC) UK energy scenarios upon fuel imports; analyzes how changing patterns of fuel imports impact on shipping freight work and the corresponding emissions that may need to be accommodated within the UK's emission budget; and discusses these findings in the light of wider climate change objectives.

\section{Method}

This paper applies to the shipping sector a scenario analysis framework devised at the Tyndall Centre for Climate Change Research (Manchester, UK), and previously applied to the whole UK energy system [24] and aviation [25]. The framework is outlined in Figure 1. A bespoke energy model, ASK for ships, calculates $\mathrm{CO}_{2}$ emissions from shipping in a given year on the basis of the quantity of commodity shipped in that year, the distance it is shipped and the carbon intensity of shipping [26]. Energy system data to calculate baseline emissions is readily available from UK energy and trade statistics $[23,27,28]$. The future UK energy system has been the subject of considerable analysis by bodies such as the CCC and DECC [2,29]; this article builds on the work of DECC to explore, for the first time, the consequences of energy system change for UK shipping.

\section{- Calculating the $\mathrm{CO}_{2}$ emissions from shipping}

A bespoke energy model, ASK for Ships, is used to estimate the $\mathrm{CO}_{2}$ emissions from the shipping of fossil fuel into the UK in the baseline year (2006) and in 2050 [26]. The quantity of these imports is taken from trade statistics disaggregated by country of loading $(\mathrm{X}$ and $\mathrm{Y})$ $[27,28]$. To quantify the freight work associated with energy trade, the distance between trading partners is estimated using online port distance calculators [101]. The total freight work attributable to UK shipping is then mapped onto relevant ship types according to the commodity being transported. This is a significant simplification as ships frequently stop in additional ports en route to the country of unloading, or take a more indirect route. However, when considering total UK seaborne trade, including all international and domestic trade, the average distance estimate per seaborne tonne is comparable to other values (e.g., [13]).

Emission factors for vessels of differing sizes and types, measured in terms of $\mathrm{g} \mathrm{CO}_{2} / \mathrm{t}$ nautical miles, are estimated based on vessel characteristics $[4,30]$. These are calculated using Equation 1:

$$
\frac{\sum_{i=1}^{\mathrm{nME}}\left(\mathrm{ME}_{(\mathrm{i})} * \mathrm{Lf} * \mathrm{Cf}_{\mathrm{ME}(\mathrm{i})} * \mathrm{SFC}_{\mathrm{ME}(\mathrm{i})}\right)+\sum_{i=1}^{\mathrm{nAE}}\left(\mathrm{AE}_{(\mathrm{i})} * \mathrm{Lf} * \mathrm{Cf}_{\mathrm{AE}(\mathrm{i})} * \mathrm{SFC}_{\mathrm{AE}(\mathrm{i})}\right)}{(\mathrm{dwt} * \mathrm{Uf} * \mathrm{~V})}
$$

Equation 1 
where available cargo capacity is in deadweight tonnes (dwt). Main and auxiliary engine size (ME and AE, respectively) are in $\mathrm{kW}$. The engine loading factor (Lf) reflects the proportion of total engine size utilized when in operation and is dependent on ship speed. Average speed and loading factors (reflective of both ship type and size) are taken from [4]. SFC reflects the specific fuel consumption of both main and auxiliary engines and is measured in $\mathrm{g} / \mathrm{kWh}$. Cf refers to the carbon based fuel emissions factor $\left(\mathrm{kg} \mathrm{CO}_{2} / \mathrm{kg}\right.$ fuel) for both heavy fuel oil and marine diesel. The utilization factor (Uf) is expressed as a percentage and reflects the fact that a vessel will not use all of its available capacity and/or travel a portion of its round trip while empty. V refers to average vessel speed in knots (nautical miles per hour).

For ships that transport oil and petroleum products, the emissions associated with auxiliary boilers for keeping cargo viscous are estimated by dividing boiler fuel consumption by the amount of transport work done [4]. This generates an emission factor for each ship size range, and this additional element is added to the main and auxiliary engine emission factor for the ship size relevant to UK activity.

Lloyd's List Intelligence provides data on vessel callings to UK ports in 2006 [31]. This allows for average vessel size per UK ship call to be estimated for different ship categories. To establish the veracity of such estimates, average ship sizes are compared with those from two other sources; averages extrapolated from Eurostats vessel traffic data [32] and average ship size based on the calling of ships since 2002, which are liable to light dues, levied on ships for the maintenance of lighthouses [33]. For some ship types, ships need to be aggregated into a more generalized category such as liquid bulk. Vessel engine size is estimated by correlating current engine size with ship capacity based on vessel characteristics supplied by Lloyds [31]. In relation to the transport of coal, authors such as Stopford describe how coal is generally carried on large bulk carriers (>100,000 dwt) [21]. For that reason, average ship size for transporting coal is calculated based on the callings of ships in excess of this size.

Since 1990, ship sizes have increased by an average of $2.5 \%$ per annum (pa), though more modest growth rates are likely out into the future $[4,34]$. To determine ship size in 2050, it is assumed that in general ships size will increase by $1 \%$ pa, in line with assumptions by the CCC and IMO with some step change in vessel size for specific fuels $[4,34]$. For example, some energy commodities are transported on larger ships, for example coal, whereas other commodities such as oil products are transported on smaller vessels. This necessitates choosing a more appropriate size or type than the general average; see [30] for a broader discussion regarding average emission factors applicable to the UK. The approximate ship size, type and emissions factor applied here for 2006 and 2050 are shown in Table $1[4,31,33,35]$. The ship type in 2050 is suggested by information (such as energy flow diagrams) available through the DECC 2050 webtool calculator [102]. Based on this information the fuel category 'oil and oil products' is taken to refer to crude oil in 2050, while gas imports refer to natural gas (the latter reflects a different size range).

\section{Energy imports in 2006}

For step 1 of the method (Figure 1), the UK's energy system and the associated fuel imports by ship must be fully described for the baseline year,to enable both the quantification of the baseline $\mathrm{CO}_{2}$ emissions for shipping fuel imports and to aid understanding of how fuel imports may change in 2050. Total final energy demand is estimated at $1972 \mathrm{TWh}$ (for a baseline year of 2006) [23]. This demand is met through the combustion of natural gas for space, water and process heating (621 TWh), oil for transport (956.6 TWh) and electricity (345.2 TWh) [23].

\section{- Oil}

The UK is both a significant producer and importer of crude and petroleum products [23]. Imports come principally from Norway, due to proximity and a good match with indigenous sources in terms of composition; additional imports come from Russia and Organization of the Petroleum Exporting Countries [23]. The production in UK domestic refineries is not well aligned to domestic demand due to the increasing penetration of diesel into the domestic road transport fleet and the demand for aviation fuel [23]. Diesel is imported mainly from Europe, with imports of aviation fuel principally from Qatar and Kuwait [23].

\section{- Natural gas}

Natural gas is both produced domestically and imported, with the UK having become a net gas importer in 2004 [23]. Imports in 2010 accounted for just under $50 \%$ of the UK's gross (consumption plus exports) gas demand. Traditionally, natural gas imports have been pumped; pipelines transport gas from Norway, the Netherlands and Belgium. In 2005, however, imports of liquid natural gas (LNG) began at the Isle of Grain LNG import facility (Kent, UK) and two new terminals at Milford Haven (UK) became operational in 2009 [36]. Imports of LNG have increased steadily as a consequence and in September 2010 imports from shipped LNG surpassed the gas imported via pipeline for the first time [23]. 


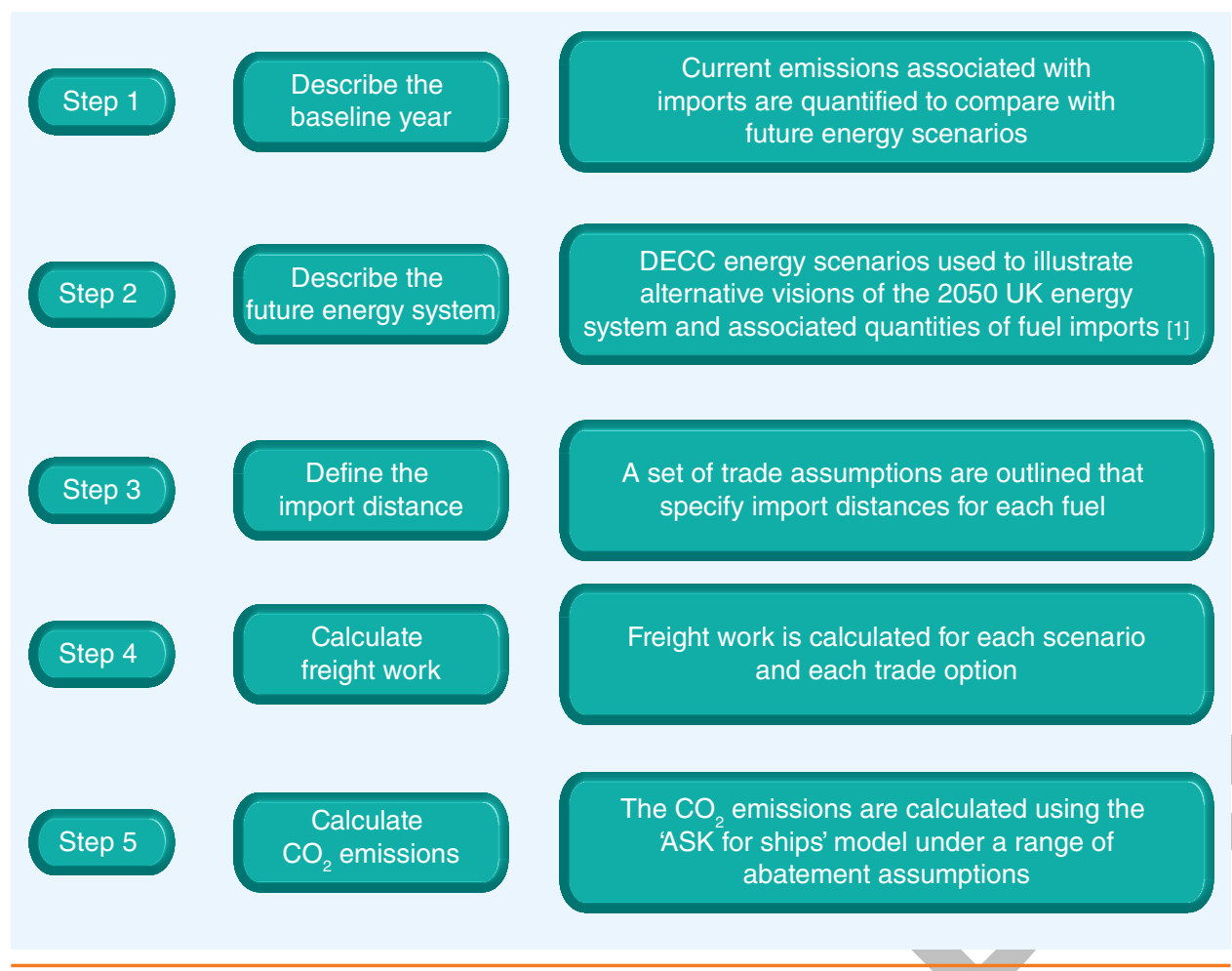

Figure 1. Method for estimating $\mathrm{CO}_{2}$ emissions from the shipping of fuel in 2050.

DECC: Department of Energy and Climate Change.

- Coal

A similar picture of imports and domestic production exists for coal as for the other fossil fuels. Imports have grown steadily since the 1970s, and exceeded domestic production for the first time in 2001 [23]. The UK imports steam coal for power stations, coking coal for steel production and anthracite, with steam coal making up $75 \%$ of imports. Russia supplies $46 \%$ of steam coal, Colombia $32 \%$ and the USA $12 \%$ [23].

- Renewables

The renewable energy sector is more diverse than others, representing several distinct fuels. Specifically, it includes wood- and plant-based fuels, straw and poultry litter, landfill and sewage gas, waste, geothermal, solar, heat pumps, hydro, wind, wave energy and liquid biofuels. In terms of domestic renewable primary energy production (in 2010): landfill and sewage gas contributed 30\%; wood, wood waste, agricultural litter, plant-based biomass and liquid biofuel accounted for approximately $31 \%$; waste contributed $18 \%$; and $29 \%$ consisted of geothermal energy and renewable sources of electricity such as wind and hydro. In energy terms, the UK imports an equivalent quantity of biomass as is produced domestically, but by contrast over three times the quantity of biofuels are imported as produced domestically. Because traded material is not distinguished in terms of end use it is difficult to accurately determine the origin of imported biomass and biofuels. However, data on EU biomass flows suggests that Scandinavia and Eastern Europe are likely sources of biomass, with countries such as Spain supplying products such as oil seed mash [37]. For bioethanol it is likely that the USA and Brazil represent key trading partners, but this is speculative [38].

Despite the UK's significant indigenous fuel resources, it has been a net importer of fuel since 2004 , as illustrated in Supplementary Figure 1. The import of energy commodities, including crude petroleum, refined oil, liquid gas and coal is an important market for the shipping sector, representing a significant proportion of total commodities transported by ship (excluding domestic trade), as demonstrated in Supplementary Table 1 [35].

Quantity of imports alone provides an incomplete account of the dependencies inherent in the UK's fuel consumption. The geographic distribution of the UK's trading partners offers an equally important insight into the extent to which the UK is reliant on an extensive (and globalized) transport chain. In 2010, the UK imported coal, oil and petroleum products, gas and biomass, and quantities of imports from each trading partner are illustrated in Supplementary Figures 2, 3 \& 4. Supplementary Figure 2 illustrates aggregate imports of oil and petroleum products, but different countries are important depending on the fuel; thus, the Middle East and Asian countries are key suppliers of aviation fuel whereas European countries are the dominant suppliers of diesel to the UK [39].

The maps demonstrate the importance of shipping to UK energy supply and key suppliers for each, although the fuels are sourced from a diverse range of countries. Patterns of trade can change in both drastic and gradual ways. The Middle East oil crisis precipitated a shift in sourcing imports away from the Middle East towards Europe, in particular Norway and Russia [35]. Imports of coal have grown steadily since the 1970 s, peaking in 2006. By contrast, the quantity of liquid gas transported by ship in 2010 increased eightfold, albeit from a relatively low base, from 2008 levels [35]. Unlike coal, which represented a gradual displacement of trading partners (i.e., increasing trade with Russia, Latvia and 
Table 1. Ship characteristics for UK shipping in 2006 and 2050.

\begin{tabular}{|c|c|c|c|c|c|c|}
\hline \multirow[t]{2}{*}{ Fuel type } & \multicolumn{3}{|c|}{2006} & \multicolumn{3}{|c|}{2050} \\
\hline & Ship type & Size (dwt) & $\begin{array}{l}\text { Emission factor } \\
\left(\mathrm{g} \mathrm{CO}_{2} / \mathrm{tnm}\right)\end{array}$ & Ship type & Size (dwt) & $\begin{array}{l}\text { Emission factor } \\
\left(\mathrm{g} \mathrm{CO}_{2} / \mathrm{tnm}\right)\end{array}$ \\
\hline Crude oil & Crude tanker & 110,000 & 10 & Crude tanker & 171,000 & 8 \\
\hline Oil products/biofuel & Product tanker & 7800 & 45 & Product tanker & $25,000-100,000^{\dagger}$ & $13-25$ \\
\hline Coal & Dry bulk & 163,000 & 6 & Dry bulk & 252,000 & 5 \\
\hline Liquid gas & LPG carrier & 5200 & 44 & LNG carrier & 96,000 & 18 \\
\hline \multirow[t]{2}{*}{ Solid biomass } & General cargo & 3000 & 36 & General cargo & $7000^{+}$ & 30 \\
\hline & & & & Bulk carrier & $30,000-120,000^{+}$ & $7-13$ \\
\hline Nuclear & Container & 3500 & 67 & Container & 5422 & 28 \\
\hline
\end{tabular}

Columbia over the past decade), the increase in liquid gas imports reflect trade with a new partner, namely Qatar.

\section{The UK energy system in 2050}

Step 2 of the process requires the energy system in 2050 to be described in terms of quantity of fuel imports (Figure 1). In so doing, it allows the impact of changes in demand for fuel to be explored for UK shipping. To meet the UK Government's legally binding $80 \%$ emission reduction target by 2050 and associated shorter-term emission budgets, there will be major changes to UK energy consumption and supply. While there are a number of energy scenarios that explore the UK's 2050 climate change targets (e.g., see $[29,40])$, the analysis in this paper takes the energy systems described in four DECC energy scenarios as a starting point [2]. The DECC energy scenarios were chosen as they inform the UK's legally binding climate change targets; thus, this analysis extends the scenarios to consider, for the first time, the knock-on effect of energy system change upon the shipping sector. The development of the DECC scenarios has been informed by modeling using the MARKAL model; MARKAL is a cost optimisation model that devises the most costeffective way of achieving a specified target under a given set of technology assumptions. The MARKAL model and its use in energy policy making are discussed in Ekins et al. [40]. In the DECC scenarios, the electricity grid will have to become decarbonized, with electricity generated from renewable sources, nuclear or from fossil fuels with CCS $[2,102]$. Biomass may be co-fired with coal in conjunction with CCS (BECCS) resulting in negative $\mathrm{CO}_{2}$ emissions; it may also be combusted in dedicated biomass power stations or for combined heat and power. Combustion of gas and coal for heating disappears almost completely by 2050 , replaced by electricity and renewable heat technologies such as heat pumps and biomass combustion. Conventional internal combustion engines are unlikely to be used significantly, with road transport powered by electricity, hydrogen and biofuels - passenger trains will be electrified. To respond to these changes, the grid is likely to be larger and smarter in terms of managing demand to balance supply, particularly to allow for the large-scale penetration of intermittent renewables.

Beyond these headline messages, much about the energy system in 2050 is uncertain; energy needs could be met in a myriad of ways with different levels of energy efficiency and supply mixes. The four DECC energy scenarios take different views about the costs and availability of demand and supply technologies to produce a core 'cost optimized' scenario and three alternative scenarios [2]. Figure 2 illustrates the Core Markal scenario 'core', the step change assumptions underpinning the three alternatives and final demand for each scenario. The DECC scenarios are characterized by different levels of energy efficiency and demand, met by a range of penetrations of the supply technologies previously highlighted. In Supplementary Figure 5, the implications of assumptions for the amount of energy supplied by each fuel are illustrated.

The scenarios are characterized by different requirements for indigenous and imported fuels. Taking the 'higher CCS, more bioenergy' scenario as an example, ('CCS') reductions in per capita energy consumption of $43 \%$ are assumed, and significant use of bioenergy with CCS to create negative emissions leaves 'emissions space' for combusting fossil fuels [2]. This allows for the continued use of petroleum products in transport leading to significant levels of oil imports, along with imports of coal and gas. By contrast, in the 'higher nuclear, less energy efficiency' scenario ('nuc'), the widespread deployment of CCS has not been possible, hence no significant use of coal, and there has been a high level of electrification in transport and for heating. In this case, coal is supplied domestically and there are lower oil imports when compared to the CCS scenario.

Table 2 sets out the quantities of fuel imports for each of the scenarios [102] and the energy density of the fuels used to derive them [41]; these quantities are inputs into 


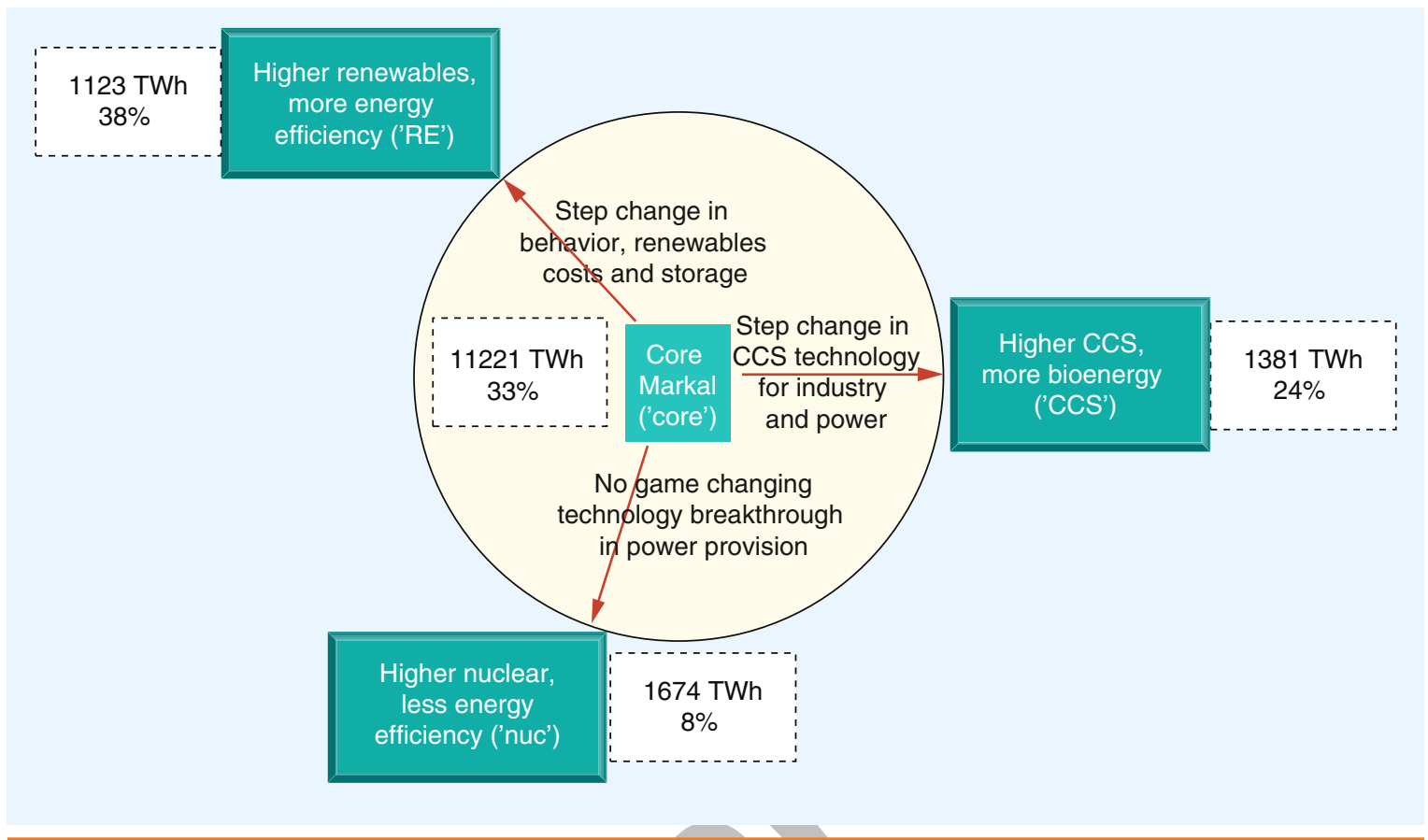

Figure 2. The four Department of Energy and Climate Change energy scenarios for 2050.

Data taken from [1].

the 'ASK for ships' model. Biomass imports in 2006 are estimated from [41]. Energy density values are assumed to be same in 2050 as in 2006 .

Trade assumptions in 2050

Step 3 of the scenario process requires the import distance for the energy commodities to be defined (Figure 1). To explore the influence of trading partners and the resultant distance fuel travels upon shipping $\mathrm{CO}_{2}$ emissions, three contrasting sets of assumptions about future trade patterns were articulated. While the different options are based on diverse sources of literature, in each case the assumptions have been considered within fossil fuel resource estimates [42] and data on future trends
[43]. These options must be seen as thought experiments allowing different assumptions to be explored rather than predictions for 2050, when trading partners will depend on many factors such as geopolitics and price.

\section{- Option 1: current import patterns}

Option $1(\mathrm{O} 1)$ proposes continued imports from existing key suppliers. In 2050, the demand for oil and transport fuels will be different from 2006, with reduced demand for motor spirit, as transport is powered by electricity or other sources but continued high demand for aviation fuel due to a lack of alternatives [2,39]. In this regard, and given that Organization of the Petroleum Exporting Countries' shares of world oil production is set to rise, Table 2. 2050 Fuel imports proposed for the Department of Energy and Climate Change energy scenarios.

\begin{tabular}{|c|c|c|c|c|c|c|}
\hline \multirow[t]{2}{*}{ Fuel } & \multirow{2}{*}{$\begin{array}{l}\text { Energy density } \\
\text { (MJ/kg) }\end{array}$} & \multicolumn{5}{|c|}{ Quality of fuel import (kt) by scenario } \\
\hline & & 2006 & Core Markal & $\begin{array}{l}\text { Higher } \\
\text { renewables, more } \\
\text { energy efficiency }\end{array}$ & $\begin{array}{l}\text { Higher CCS, } \\
\text { more } \\
\text { bioenergy }\end{array}$ & $\begin{array}{l}\text { Higher nuclear, } \\
\text { less energy } \\
\text { efficiency }\end{array}$ \\
\hline Nuclear & 0.0057 & 0.27 & 4 & 1.92 & 2.39 & 9.15 \\
\hline Coal & 28 & 54,008 & 17,229 & 0 & 2957 & 0 \\
\hline $\begin{array}{l}\text { Oil and oil } \\
\text { products }\end{array}$ & 42 & 120,519 & 25,371 & 24,857 & 31,543 & 10,114 \\
\hline Gas & 50 & 4453 & 648 & 1296 & 15,480 & 7704 \\
\hline Biomass & 20 & $2005^{\dagger}$ & 9540 & 6300 & 12,600 & 14,760 \\
\hline Biofuel & 42 & 75.05 & 4543 & 3000 & 6000 & 10,200 \\
\hline
\end{tabular}


this option maintains high levels of imports from those countries with large refining capacity for aviation fuel, predominately Kuwait and Saudi Arabia, as well as crude oil imports from Norway; piped gas imports continue from Norway. At present, shipped LNG is dominated by imports from Qatar [39]. To reduce this dependence, the UK diversifies imports of LNG to include Australia, already a large exporter of LNG, expanding its market through the exploitation of shale gas resources for export [44]. Coal imports continue from Russia, the USA and Columbia. While small in 2010 relative to imports of fossil fuels, imports of solid biomass and liquid biofuels will be considerable in 2050. Solid biomass is imported as pellets from Canada, which has invested in pellet production facilities and as olive cake from Spain [45]. Liquid biofuels are imported from Brazil and South Africa $[45,46]$.

\section{- Option 2: reducing import distance}

Option 2 (O2) explores the impact of sourcing fossil fuels as close to the domestic market as possible. Changing import patterns in this way from the current globalized supply chains may be to reduce transport costs should the price of oil rise considerably, or to reduce the carbon emitted if shipping were covered by a strong emissions cap. Under this option, investment in UK refineries may be required to enable the production of middle distillates, particularly aviation fuel, with crude oil imports from Norway and Russia. Russia has the world's largest reserves of natural gas and is the world's largest piped gas exporter [47]; this option proposes that Russia is a new supplier of piped gas to the UK, with LNG exports from Norway and exploitation of UK domestic shale gas reserves. Coal is imported from Russia, and solid biomass is imported as pellets from Russia, which has invested in pellet production facilities and as olive cake from Spain [45]. Liquid biofuels are imported from Russia, which has good agricultural resources for energy crops [46].

\section{- Option 3: reduced imports from Europe}

Option 3 (O3) explores the impact of the UK sourcing fuels from outside Europe. While it is highly unlikely that the UK would not be able to access any EU and wider Europe markets, access to such markets may become restricted. In a future with very stringent climate targets, there may be intense competition for biofuels, for example. Restricted access to Russian resources could occur for geopolitical reasons such as disputes with pipeline transit countries or Russia concentrating exports on more cost-effective Asian markets [47]. Under this option, there are high levels of imports of oil products as in $\mathrm{O} 1$, in addition to crude oil imports from Saudi Arabia. This option diversifies UK imports of LNG to include Australia (as in O1) and the USA, as it exploits its reserves of unconventional gas for export. Coal imports continue from the USA and Columbia. Biofuel assumptions are the same as in $\mathrm{O} 1$ and solid biomass is imported from the USA and Canada [45].

Current trade is often dominated by one or two major suppliers with other smaller partners [28,39]. With this in mind, and to simplify the emission and distance calculations given the inherent uncertainty of estimating quantities fuel that would be imported from a particular source in 2050, the 'what if' scenario assumption is that UK demand is divided equally between the major trading partners. Table 3 summarizes the characteristics of each option in terms of country of fuel origin, proportion of shipped imports and average transport distance.

\section{Results}

- Freight work for fuel shipping

The freight work arising from the import of fuel into the UK in 2050 for each of the four energy scenarios and under three trade assumptions is illustrated in Figure 3.

\section{Effect of quantity of imported fuel}

Figure 3 demonstrates that the form of the energy system in 2050 - outlined in the contrasting energy scenarios - and, hence, demand for fuel, has implications for shipping. For the baseline year, coal and oil and petroleum products are dominant contributors to freight work; the impact of both the quantity traded and distance over which coal is transported are clearly visible. The demand for imported fuel changes according to the assumptions made within the energy scenarios and by 2050 there is expected to be less need for the shipping of coal, gas, oil and petroleum products, but new requirements for shipping biomass and biofuels. Energy demand in each scenario is illustrated in Supplementary Figure 5. Of the four, the 'higher renewable, more energy efficiency' scenario ('RE') has the lowest level of energy demand due to a reduction in per capita energy consumption of $53 \%$, delivered through a high penetration of demand reduction in buildings and the largest switch to public transport of all scenarios [2]. This low energy demand, coupled with the high proportion of primary energy supply from renewables, results in the lowest demand for imported fuels in 2050 and the lowest amount of freight work (Supplementary Figure 5).

The highest freight work in 2050 arises in the 'higher CCS, more bioenergy' scenario ('CCS'). While this is not the highest in terms of energy demand or primary supply, considerable quantities of gas, oil and bioenergy are shipped. The extensive deployment of CCS allows for the continued use of gas for thermal generation, and BECCS makes available emission space for fossil fuels for 


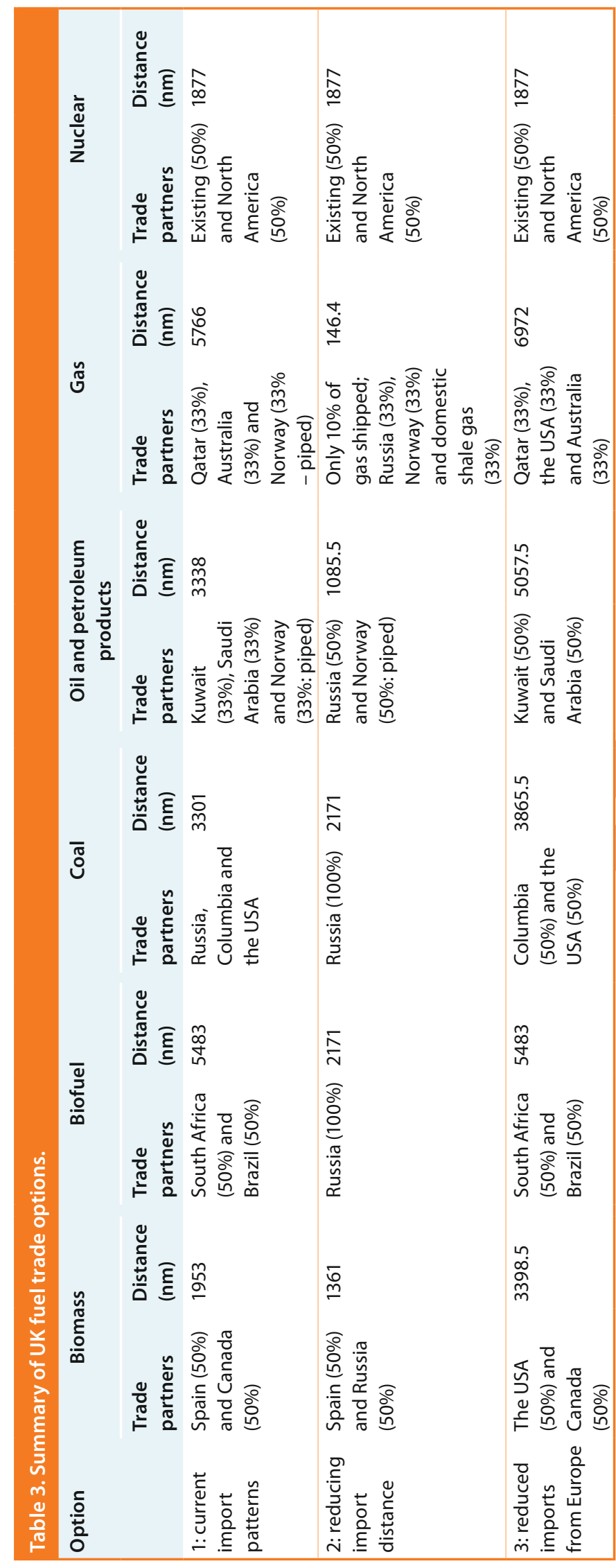

transport [2]. The 'higher nuclear, less energy efficiency' ('nuc') scenario has the highest energy demand in 2050 as a consequence of the lowest reduction in energy demand per capita (31\%) [2]. 55\% of primary supply is provided by nuclear power, which is a highly efficient energy source in terms of the quantity of fuel required (Supplementary Figure 5). Shipments of nuclear fuel are generally few in number and special ships not required, so fuel can be carried on general cargo or container vessels [48].

\section{Effect of import distance}

The amount of a particular fuel imported is only one element of freight work, the other being the distance over which the fuel is shipped. Figure 3 illustrates the impact of source country on freight work using trade assumptions in Table 3. Under O2, demand for shipping (freight work) arises from the import of coal, biomass, biofuels and oil from Russia, depending on the supply mix in the energy scenario. Freight work is highest in the 'core Markal' scenario ('core'), due the quantity of coal imported. Under O2, fuels are sourced from within Europe; freight work is thus reduced both because of the shorter shipping distances relative to the baseline and the other options, but also because oil and gas can be imported via pipeline. Investments in pipeline networks, for example to increase imports of Norwegian gas [39], could drive a shift away from shipped LNG, bought on open markets [49], if the UK looked to enhance energy security by committing to very long-term contracts with European partners such as Norway. While pipeline transport consumes energy, it is less energy intensive than shipping [50] and the associated emissions are outside the scope of this paper. With this radical change in import patterns, large reductions in the amount of freight work are observed compared to the baseline year.

Under O3, fuels are sourced from outside Europe and the impact of the longer distances travelled on freight work is apparent; the freight work is highest of the three trade assumptions. The 'CCS' scenario is very different to the baseline in terms of the relative quantities of fuels imported, yet the amount of freight work is similar. Freight work for transporting oil and petroleum products under $\mathrm{O} 3$ is comparable with the baseline except under the nuc scenario. Following on from this, oil/petroleum products dominate freight work if fuel is sourced outside the EU. In 2050, there will be greater demand for the transport of LNG in all but the core Markal scenario.

- Carbon emissions from fuel imports in 2050

Within the ASK Ships model, $\mathrm{CO}_{2}$ emissions are calculated by applying to the freight work an emission factor for each of the ship types used to transport a 


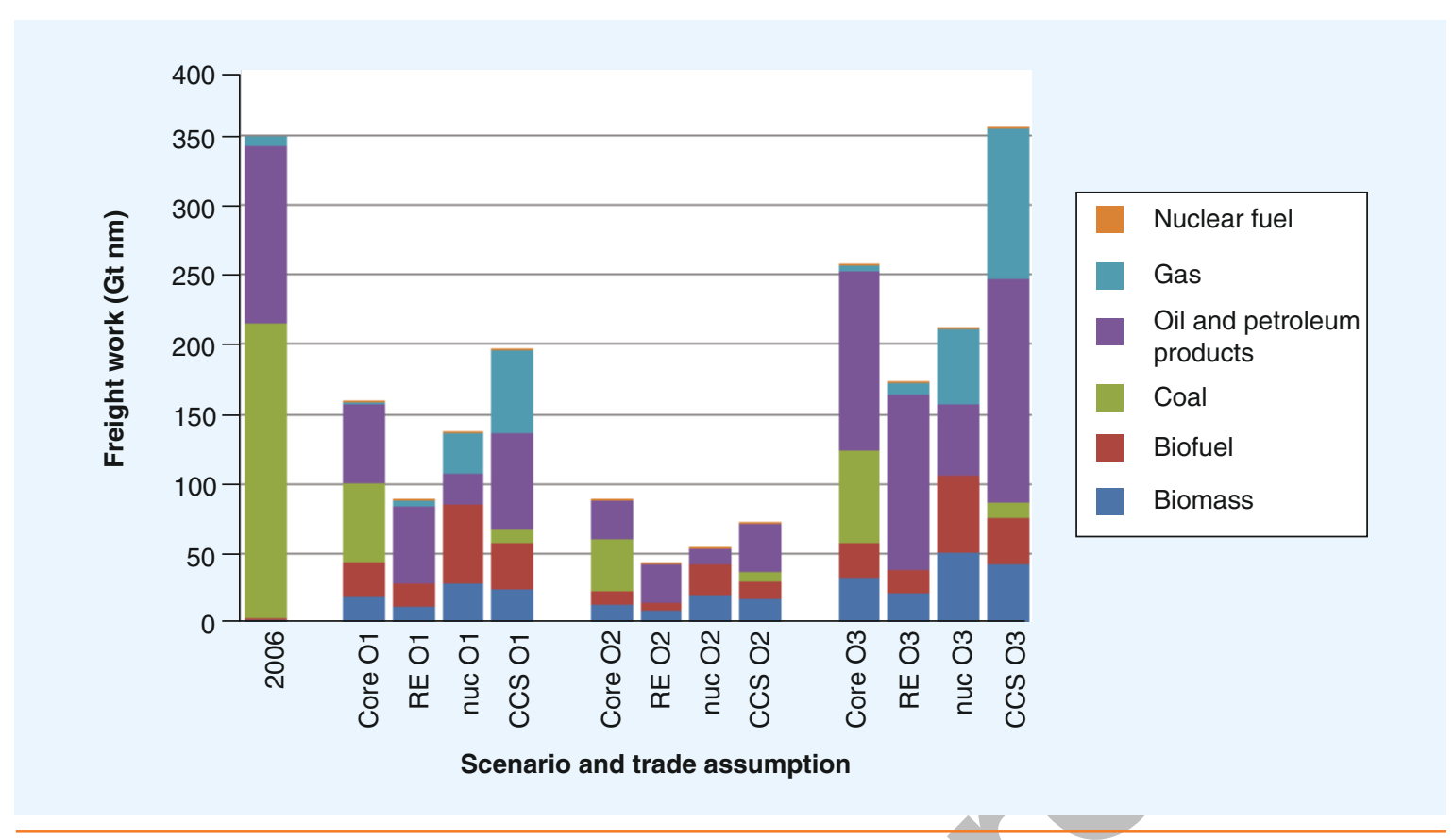

Figure 3. Freight work in 2050 (Gt nm) for each Department of Energy and Climate Change energy scenario under trade assumptions option 1, option 2 and option 3.

CCS: Higher CCS, more bioenergy scenario; Core: Core Markal scenario; nm: Nautical mile; nuc: Higher nuclear, less energy efficiency scenario; O1: Option 1; O2: Option 2; O3: Option 3; RE: Higher renewable, more energy efficiency scenario.

Please see color figure at http://www.future-science.com/doi/full/10.4155/CMT.12.67.

particular fuel. Unless specified otherwise it is assumed that fuel in 2050 is transported in the same type of ship as in 2006 and that ships increase in size by $1 \%$ annually. The quantity and transport distance will, however, impact on the size and type of vessel, particularly if there is a significant change to existing trade patterns or significant expansion in the market, such as is the case in the trade of biomass and biofuel, resulting in the adoption of bespoke vessels. For that reason, within the 'nuc' and 'CCS' scenarios in options 1 and 3 , biomass and biofuel are assumed to be transported on bulk carriers and product tankers of 120,000 and $100,000 \mathrm{dwt}$, respectively. For those options within the other scenarios, bioenergy trade is assumed to be served by smaller vessels $(60,000 \mathrm{dwt}$ bulk carriers and 30,000 product tankers, respectively). Similarly, within $\mathrm{O} 2$, biomass and biofuel in the 'nuc' and 'CCS' scenarios is assumed to be transported on bulk carriers and product tankers of 30,000 and 20,000 dwt, respectively. In the other scenarios, biomass and biofuel is assumed to be transported in large general cargo carriers (7000 dwt) while the size of product tankers remains unchanged at 20,000 dwt.

Figure 4 illustrates $\mathrm{CO}_{2}$ emissions for each of the scenarios for each of the import options and the baseline. For the baseline year, oil and petroleum products' dominant contribution to $\mathrm{CO}_{2}$ emissions is a consequence of the greater emission intensity of petroleum product tankers compared to other fuel carriers (with the exception of liquid gas carriers [30]) due to their size and need for auxiliary boilers.

To consider first how the form of the energy system influences the associated $\mathrm{CO}_{2}$ emissions from the shipping of the fuel, it is useful to focus on a single trade pattern, in this case a continuation of current import patterns (O1). The four energy system scenarios result in different levels of $\mathrm{CO}_{2}$ emissions, with the emissions arising from the import of fuel in the highest emitting scenario ('CCS' scenario) nearly twice of those in the lowest emitting scenario ('RE'). The proportion of fuel import $\mathrm{CO}_{2}$ emissions from shipping biofuels into the UK is pronounced, accounting for between $37 \%$ and $61 \%$ depending on the scenario. This high proportion of $\mathrm{CO}_{2}$ emissions is a consequence of the type of ship in which biofuels are transported, namely those designed for oil products and general cargo, which have a high emissions intensity compared to other ship types [30]. This proportion would be even higher, however, had it been assumed that ships used for bioenergy transportation in the future remain similar to those currently serving the UK. Product tankers visiting the UK are currently small vessels $(<10,000 \mathrm{dtw})$ with 


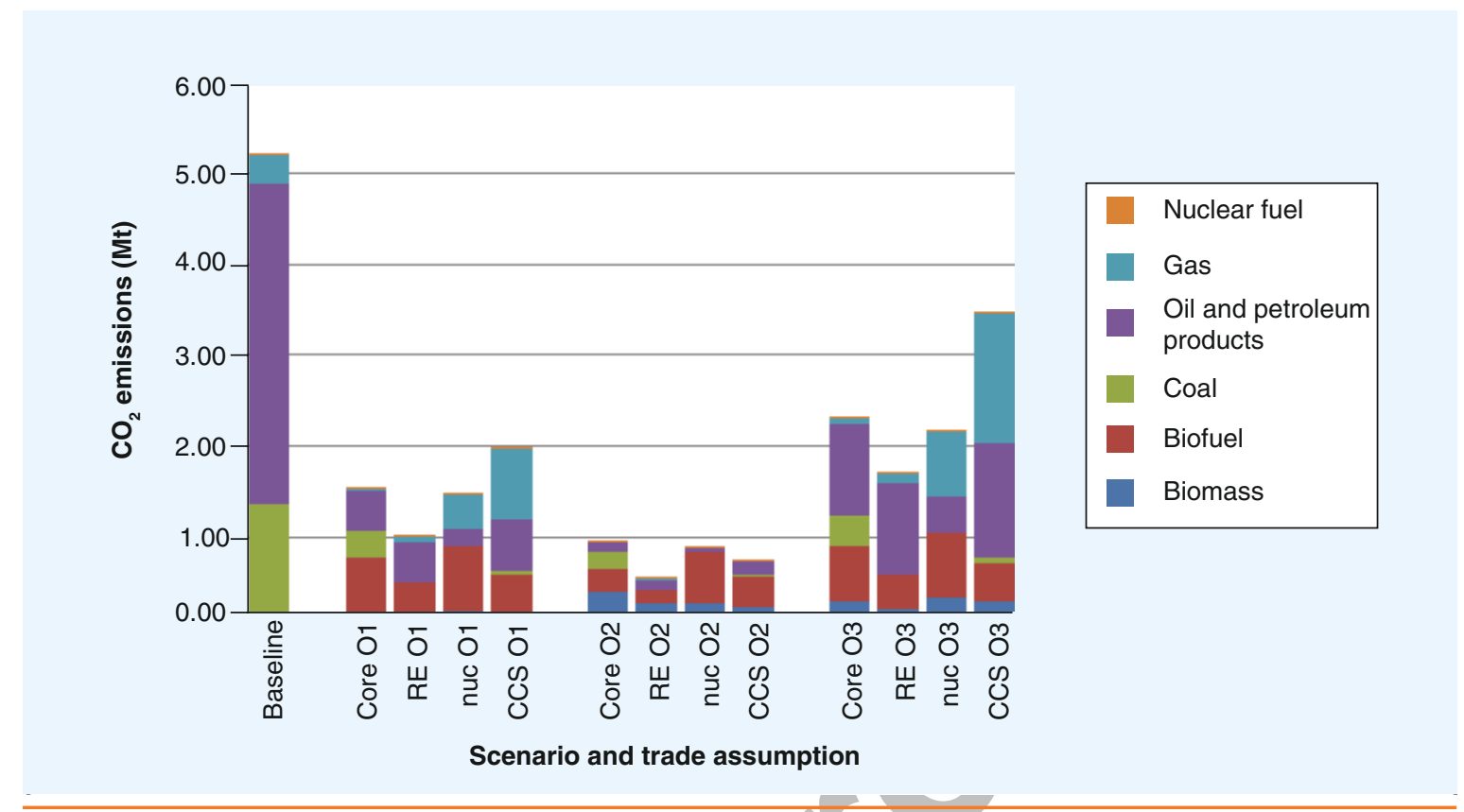

Figure 4. $\mathrm{CO}_{2}$ emissions arising from fuel imports in 2050 for each trade assumption.

CCS: Higher CCS, more bioenergy scenario; Core: Core Markal scenario; nuc: Higher nuclear, less energy efficiency scenario; O1: Option 1; O2: Option 2; O3: Option 3; RE: Higher renewable, more energy efficiency scenario.

Please see color figure at http://www.future-science.com/doi/full/10.4155/CMT.12.67.

a high emission factor ( $46 \mathrm{gCO}_{2} / \mathrm{t}$ nautical mile). Thus, if the ship type used for bioenergy transport remained unchanged and growth in ship size was just $1 \%$ annually, the bioenergy emissions associated with the scenarios (Figure 4) would be effectively doubled. However, here larger ship sizes (25,000-100,000 dwt) are chosen to represent the bioenergy shipping market in 2050, given the sector's significant expansion [51]. The results for biomass are also contingent on the properties of the fuel shipped such as energy density

\begin{tabular}{|c|c|c|c|c|c|}
\hline \multirow[t]{2}{*}{ Trade assumption } & \multicolumn{5}{|c|}{ Scenario } \\
\hline & Baseline & Core & RE & Nuc & CCS \\
\hline \multicolumn{6}{|l|}{ Option 1} \\
\hline Shipping $\mathrm{CO}_{2}$ emissions (Mt) & 5.20 & 1.01 & 1.47 & 1.97 & 1.53 \\
\hline Reduction from baseline (\%) & & 81 & 72 & 62 & 70 \\
\hline \multicolumn{6}{|l|}{ Option 2} \\
\hline Shipping $\mathrm{CO}_{2}$ emissions (Mt) & 5.20 & 0.94 & 0.53 & 0.87 & 0.73 \\
\hline Reduction from baseline (\%) & & 82 & 90 & 83 & 86 \\
\hline \multicolumn{6}{|l|}{ Option 3} \\
\hline Shipping $\mathrm{CO}_{2}$ emissions (Mt) & 5.20 & 2.31 & 1.71 & 2.17 & 3.46 \\
\hline Reduction from baseline (\%) & & 56 & 67 & 58 & 33 \\
\hline
\end{tabular}

or moisture content, which would impact on the quantities required.

Overall, changing demand for fuel alone could reduce the $\mathrm{CO}_{2}$ emissions associated with energy imports by up to $81 \%$ as shown in Table 4. For a given energy system, $\mathrm{CO}_{2}$ emissions can be significantly reduced by reducing the import distance, as illustrated in Figure 4. Under trade assumption $\mathrm{O} 3$, where fuel is sourced from further afield, $\mathrm{CO}_{2}$ emissions reductions are between 67 and $33 \%$, depending on the energy scenario. These levels of emissions contrast with those under $\mathrm{O} 2$, where import distances are significantly less and where reductions of between $90 \%$ and $82 \%$ are achieved. The reductions in the later are contingent on piped imports and under this trade pattern the import of biofuels, for which shipping is likely to be the dominant mode of transport, is responsible for the majority of shipping $\mathrm{CO}_{2}$ emissions.

Up to this point, estimates of $\mathrm{CO}_{2}$ emissions in 2050 arising from the shipping of fuels have not taken into account the potential improvements in the carbon intensity of shipping. Historically, the fuel efficiency of shipping has been improving at a rate of $1.1 \%$ pa (Mtoe/t nautical mile) through a combination of increasing ship size, new technology and operational practices. In the future, there is scope for further carbon intensity reductions from a combination of larger ships, new fuels or propulsion systems, more widespread use of fuel-saving technologies and operational changes 
$[4,52]$. To explore, in a simple analysis, the impact of different levels of improvements in carbon intensity on emissions in 2050, three different levels of abatement are considered taken from work by the CCC [34] and applied across all ship types.

As an example, the impact of improving the carbon intensity of shipping is illustrated for the core scenario in Table 5.

The least ambitious abatement assumptions $(22 \%)$, achieving limited abatement beyond the EEDI (Supplementary Table 2) illustrates $\mathrm{CO}_{2}$ emission reductions of between 65 and $86 \%$ depending on trade (Table 5). The greatest absolute emission reductions are achievable when fuel is transported over the shortest distance (O2). However, similar absolute reductions could be achieved when fuel is transported over longer distances (O3) with high abatement.

The levels of energy demand in the UK's energy system in 2050 and the supply technologies meeting that demand clearly impacts on the shipping of, and $\mathrm{CO}_{2}$ emissions arising from, imported fuels. The lowest shipping $\mathrm{CO}_{2}$ emissions occur in the 'RE' scenario, where efforts have been made to reduce energy demand and deploy renewable energy technologies, limiting the need for fossil fuel imports. While in all cases reductions in $\mathrm{CO}_{2}$ emissions do occur, these reductions are harder to realize the further fuel is shipped, namely under trade assumption $\mathrm{O} 3$. The potential range in emissions before considering abatement for the core scenario is $2311 \mathrm{kt} \mathrm{CO}$ maximum and $1051 \mathrm{kt} \mathrm{CO}_{2}$ minimum. When this scenario is used to illustrate the further impact of including abatement, emissions could be reduced to $368 \mathrm{kt} \mathrm{CO}$ if an abatement of $65 \%$ could be achieved under assumption $\mathrm{O} 2$; in this case the maximum emissions are approximately six-times higher than the minimum.

In the baseline year, the import of crude oil and oil products was the biggest contributor to $\mathrm{CO}_{2}$ emissions but this picture changes under each scenario in 2050. While oil imports remain an important contributor to shipping $\mathrm{CO}_{2}$ emissions, solid biomass and biofuels increase their impact - not only because of a rise in demand, but also because of the carbon intensity of the ships. The future role of coal in the UK energy system is contingent on successful deployment of CCS, and even in those energy scenarios where CCS is successfully deployed coal's contribution to emissions is significantly reduced from the baseline, as it is transported in larger bulk carriers than in 2006, which are less carbon intensive than other ship types (Table 1).

As demand for coal and crude oil reduces and demand for biofuels and aviation fuel increase, imports are likely to become more carbon intensive. Gas and crude oil are currently piped into the UK

\begin{tabular}{|c|c|c|c|c|}
\hline \multirow[t]{2}{*}{ Trade assumption } & \multicolumn{4}{|c|}{ Abatement (\%) } \\
\hline & 0 & 22 & 48 & 65 \\
\hline \multicolumn{5}{|l|}{ Option 1} \\
\hline $\mathrm{CO}_{2}(\mathrm{kt})$ & 1535 & 1197 & 798 & 537 \\
\hline Reduction from baseline (\%) & 70 & 77 & 85 & 90 \\
\hline \multicolumn{5}{|l|}{ Option 2} \\
\hline $\mathrm{CO}_{2}(\mathrm{kt})$ & 942 & 735 & 490 & 330 \\
\hline Reduction from baseline (\%) & 82 & $86^{+}$ & 91 & 94 \\
\hline \multicolumn{5}{|l|}{ Option 3} \\
\hline $\mathrm{CO}_{2}(\mathrm{kt})$ & 2311 & 1803 & 1202 & 809 \\
\hline Reduction from baseline (\%) & 56 & 65 & 77 & $84^{\dagger}$ \\
\hline
\end{tabular}

as well as shipped, and pipelines are likely to remain important for these fuels. Although liquid biofuels are set to become an increasingly important commodity, centres of production are geographically located such that there is no alternative to supplementing domestic production with shipped imports. At present, only small amounts of solid biomass are imported into the $\mathrm{UK}$ in comparison to other fuels. In the future, as biomass becomes more important and regions invest in new production facilities, there is the potential for those imports to become less emission intensive.

\section{Conclusions}

Shipping faces a radical transformation if low-carbon energy transitions are to be successful. Aside from measures to directly abate the emissions from the sector itself, shipping's pivotal role in transporting energy resources around the globe will lead to new challenges as nations strive towards their climate change objectives. As Anderson and Bows demonstrate, this will require the sector to reduce absolute $\mathrm{CO}_{2}$ emissions by $15 \%$ by 2020 , with reductions of the order of $6 \%$ per year beyond 2030 [8]. Taking the UK as an example, this paper illustrates how imports of fossil fuels, which make up around $50 \%$ of total imports, shift dramatically under a suite of low-carbon energy scenarios, illustrating how changing demand for energy commodities may contribute to achieving the reductions required.

Future energy demand and supply will have a considerable impact both on the shipping sector and correspondingly on the $\mathrm{CO}_{2}$ emissions arising from the import of fuels. While oil and oil products are currently the most important contributors to freight work and $\mathrm{CO}_{2}$ emissions, biofuels and solid biomass become increasingly dominant with new markets requiring new or retro-fitted ships travelling between Europe 
and centres of production in America and Africa. The emission intensity for the ships transporting bioenergy is a key determinant of shipping $\mathrm{CO}_{2}$ emissions in 2050. In 2006, biomass was shipped in general cargo ships, but the potential quantity of imports in 2050 suggests transport in larger bulk carriers is not only likely, but also essential, if it is to avoid significantly contributing to shipping emissions. Similarly, the transport of biofuels will necessitate dedicated biofuel ships, which given assumptions regarding the quantities being moved around the globe, are unlikely to be as small and emission intensive as existing product tankers.

The distances over which fuels travel are a further crucial factor in determining future emissions and the impact of import distance on $\mathrm{CO}_{2}$ emissions has been explored through three sets of trade assumptions. The energy landscape is highly fluid, however, changing as new fossil reserves are discovered or new techniques, such as fracking, become commercialized. This offers the potential for new trading partners, such as the USA for LNG, and suppliers of fuel in 2050 will likely be different to those proposed in this analysis. The clear message emerges that the greatest absolute reductions in $\mathrm{CO}_{2}$ emissions are achievable when fuel is transported over the shortest distance. There are, however, operational and technical options for improving the carbon intensity of shipping, for example, towing kites could be used to provide additional propulsion, and similar absolute reductions could be achieved when fuel is transported over longer distances as long as there is high $\mathrm{CO}_{2}$ emission abatement in the shipping sector. Penetration of technical and operational measures will be driven by energy efficiency-focused policies such as the EEDI and Ship Energy Efficiency Management Plan, as well as by fuel price as operators seek to reduce costs, but it has to be recognized that the shipping sector currently faces less pressure to decarbonize than those within the EU ETS or UK climate change targets. Should the sector be included in UK climate change policies, it will be need to be further incentivized if reductions of the scale required are to be achieved.

In light of the currently slow progress on tackling the $\mathrm{CO}_{2}$ emissions associated with shipping [8,20], this article shows how changes to patterns of demand, specifically a reduction in demand, has a profound impact on shipping emissions. Even ignoring carbon intensity improvements desirable within a global effort to remain committed to avoiding $2^{\circ} \mathrm{C}$ of warming, the low-carbon energy transition in the UK reduces $\mathrm{CO}_{2}$ emissions from shipping by up to $81 \%$ and highlights the potential of demand management as a means to reduce the climate change impact of the shipping sector.

\section{Future perspective}

The analysis in this paper suggests many fruitful directions for further research. While fuel imports have been the focus here, other sectors of the economy bear further examination, particularly container transport, which has grown significantly in recent years. Although structural changes to the UK energy system will reduce the emissions arising from the shipping of fuels into the UK, growth in the shipping of other goods (such as containers) could negate the impact of a reduction in the demand for the shipping of energy commodities. Thus, it is only with a full assessment of the cumulative $\mathrm{CO}_{2}$ emissions arising from all shipped imports and exports from a baseline until 2050 that the full implications of shipping for UK emission budgets can be assessed. These emissions must also be placed within the debate of the scale of reductions required, given that the UK's reductions targets may not be enough for the UK to make its fair contribution to avoiding 'dangerous' climate change.

The approach taken to estimating emissions is simplified. The impact of new biomass conversion technologies is not considered, and energy densities of fuel are kept constant between 2006 and 2050. Along the same lines, future trade is restricted to two or three dominant suppliers and levels of abatement applied as a percentage change across all ship types. A more rigorous analysis would therefore consider trade patterns more in line with those currently seen, with larger numbers of trading partners. Not all technological approaches to abatement are applicable to all ship types, so there is benefit in unpacking the coarse application of abatement to apply measures appropriate to specific ship types.

From a practical perspective, if the reductions in shipping $\mathrm{CO}_{2}$ emissions that the analysis in this paper suggests are possible are to be achieved, research needs to focus these most effective approaches to reducing $\mathrm{CO}_{2}$ emissions, and how barriers to achieving these could be overcome.

\footnotetext{
Supplementary data

To view the supplementary data that accompany this paper please visit the journal website at: http://www.future-science.com/doi/ full/10.4155/CMT.12.67.

Financial \& competing interests disclosure

The authors have no relevant affiliations or financial involvement with any organization or entity with a financial interest in or financial conflict with the subject matter or materials discussed in the manuscript. This includes employment, consultancies, honoraria, stock ownership or options, expert testimony, grants or patents received or pending, or royalties.

No writing assistance was utilized in the production of this manuscript.
} 
Background

- The UK must decarbonize its energy system to meet climate change targets.

- Decarbonization of the energy system will impact on the shipping sector, which currently imports significant quantities of fuel into the UK. Method

- A five-step process for exploring the impact of energy system changes on the shipping sector is outlined.

- The method for calculating freight work and $\mathrm{CO}_{2}$ emission arising from the import of commodities is outlined.

Results

- In 2006, coal is the largest contributor to freight work, but oil products contribute the highest proportion of $\mathrm{CO}_{2}$ emissions from shipping.

- Changing demand for fuel as a consequence of energy system change impacts greatly on the shipping sector; by 2050 biofuels and biomass become dominant energy commodities.

- The distance over which fuel travels is important and the greatest reductions in absolute $\mathrm{CO}_{2}$ emissions are achieved when fuel is sourced close to the UK.

Conclusion

- The article demonstrates the potential of demand management to reduce the $\mathrm{CO}_{2}$ emissions from the shipping sector.

\section{References}

Papers of special note have been highlighted as:

- of interest

-. of considerable interest

1 Department of Energy and Climate Change. Climate Change Act 2008. Department of Energy and Climate Change, London, UK, 103 (2008).

2 Department of Energy and Climate Change. The Carbon Plan: Delivering our Low Carbon Future. Department of Energy and Climate Change, London, UK (2011).

- Sets out four energy scenarios exploring how UK climate change targets may be achieved.

3 Eyring V, Kohler HW, Lauer A et al. Emissions from international shipping: 2. Impact of future technologies on scenarios until 2050. J. Geophys. Rese. Atmos. 110(D17), (2005).

4 Buhaug Ø, Corbett JJ, Endresen Ø et al. Prevention of Air Pollution from Ships. Second IMO GHG Study 2009 Update of the 2000 IMO GHG Study-Final Report Covering Phase 1 and Phase 2. International Maritime Organization, London, UK (2009).

- Review of measures to mitigate emissions from ships.

5 Committee on Climate Change. Scope of Carbon Budgets: Statutory Advice on Inclusion of International Aviation and Shipping. Committee on Climate Change, London, UK (2012).

6 UNFCCC. Subsidiary Body for Scientific and Technological Advice. FCCC/SBSTA/1996/9/ Add.2. UNFCCC, Bonn, Germany (1996).

7 UNFCCC. Subsidiary Body for Scientific and Technological Advice. FCCC/SBSTA/1996/9/ Add.1. UNFCCC, Bonn, Germany (1996).

8 Anderson K, Bows A. Executing a Scharnow turn: reconciling shipping emissions with international commitments on climate change. Carbon Management 3(6), XXXXXX, (2012).

9 Australian Shipowners' Association, Royal Belgian Shipowners' Association, Norwegian Shipowners' Association, The Swedish Shipowners' Association, British Shipping. A Global Cap-and-Trade System to Reduce Carbon Emissions from International Shipping. The Chamber of Shipping, London, UK (2009).

10 Gilbert P, Bows A, Starkey R. Shipping and Climate Change: Scope for Unilateral Action. University of Manchester Sustainable Consumption Institute, Manchester, UK (2010).

11 Bows A, Gilbert P, Anderson K. Accounting for and influencing shipping emissions at a sub-global level. Presented at: International Conference on Technologies, Operations, Logistics and Modelling for Low Carbon Shipping. Glasgow, UK, 22-24 June 2011.

12 Anderson K, Bows A. Reframing the climate change challenge in light of post-2000 emission trends. Philosophical Transactions of the Royal Society A: Mathematical, Physical and Engineering Sciences 366(1882), 3863-3882 (2008).

13 Committee on Climate Change. Review of UK Shipping Emissions. Committee on Climate Change, London, UK (2011).

- Overview of the issues related to the climate impacts of UK shipping.

14 Entec UK Ltd. European Commission Directorate General Environment: Service Contracts on Ship Emissions: Assignment, Abatement and Market-Based Instruments. Entec UK Ltd, Newcastle-Upon-Tyne, UK (2005).

15 Faber J. Monitoring Emissions Under Different Allocation Options. EC Delft, Delft, The
Netherlands (2007).

Heitmann N, Khalilian S. Accounting for carbon dioxide emissions from international shipping: Burden sharing under different UNFCCC allocation options and regime scenarios. Marine Policy 35(5), 682-691 (2011).

17 Wright C. Methods of apportioning ship emissions to trading nations using shipping and trade data. Presented at: 2008 Annual Meeting of the International Maritime Statistics Forum. Gdansk, Poland, 28 April 2008.

18 Schrooten L, De Vlieger I, Int Panis L et al. Inventory and forecasting of maritime emissions in the Belgian sea territory, an activity-based emission model. Atmospheric Environment 42(4), 667-676 (2008).

19 Faber J, Eyring V, Selstad E et al. Technical Support for European Action to Reducing Greenhouse Gas Emissions from International Maritime Transport. CE Delft, Delft, The Netherlands (2009).

20 Gilbert P, Bows A. Apportioning international shipping emissions to nations to support the development of sub-global mitigation policies. Energy Policy doi:10.1016/j.enpol.2012.08.002 (2012) (In press).

- Considers the issue related to the apportionment of shipping emissions.

21 Stopford M. Maritime Economics. (Third Edition). Routledge, London, UK and NY, USA (2009).

- A comprehensive book focusing on martime economics.

22 Van de Voorde E. What future the maritime sector? Some considerations on globalisation, co-operation and market power. In: Global Competition in Transportation Markets: Analysis and Policy Making. Kanafani F, 
Kuroda K (Eds). JAI Press, Greenwich, CT, USA, 253-277 (2005).

23 Department of Energy and Climate Change. Digest of United Kingdom Energy Statistics. Department of Energy and Climate Change, London, UK (2011)

24 Mander SL, Bows A, Anderson Kl et al. The Tyndall decarbonization scenarios - part I: development of a backcasting methodology with stakeholder participation. Energy Policy 36(10), 3754-3763 (2008).

- Overview of the scenario framework that was adapted for the shipping analysis herein.

25 Bows A, Anderson K, Mander S. Aviation in turbulent times. Technol. Anal. Strategic Manag. 21(1), 17-37 (2009).

26 Walsh C, Bows A, Gilbert P et al. Recent trends in UK shipping emissions: implications for sectoral decarbonisation. Presented at: International Conference on Technologies, Operations, Logistics and Modelling for Low Carbon Shipping. Glasgow, UK 22-24 June 2012.

- Overview of the ASK for ships model used in this article.

27 UK Department of Transport. UK Port Trade Statistics. UK Department of Transport, London, UK (2011).

28 Eurostat. Maritime Trade Statistics. Eurostat, Luxembourg City, Luxembourg (2011).

29 Committee on Climate Change. Building a Low-Carbon Economy - the UK's Contribution to Tackling Climate Change. Committee on Climate Change, London, UK (2008).

30 Walsh C, Bows A. Size matters: exploring the importance of vessel characteristics to inform estimates of shipping emissions. Appl. Energy 98, 128-137 (2012).

31 Lloyds List Intelligence. Ship Calling Data for the UK. Lloyds's, London, UK (2010).

32 Eurostat. Vessel Traffic Data. Eurostat, Luxembourg City, Luxembourg (2011).
33 Trinity House. Report on Light Dues. Trinity House, London, UK (2008).

34 Committee on Climate Change. Review of UK Shipping Emissions - Supporting Analysis. Committee on Climate Change, London, UK (2011)

35 Eurostat. Quarterly Trade Data on Marine Traffic. Eurostat, Luxembourg City, Luxembourg (2011).

36 Lewiner C. LNG. In: European Energy Markets Observatory, 2009 and Winter 2009/2010 Dataset. Lewiner C (Ed.). Springer Science and Business Media, Berlin, Germany (2012).

37 Alakangas E, Heikkinen A, Lensu T, Vesterinen P. Biomass Fuel Trade in Europe. VTT Technical Research Centre, Jyväskylä, Finland (2007).

38 LMC. Ethanol Market Report. LMC Consultancy, Oxford, UK. (2012).

39 Department of Energy and Climate Change. Statutory Security of Supply Report. Department of Energy and Climate Change, London, UK (2011).

40 Ekins P, Anandarajah G, Strachan N. Towards a low-carbon economy: scenarios and policies for the UK. Climate Policy 11(2), 865-882 (2011).

41 Department of Energy and Climate Change. Digest of United Kingdom Energy Statistics. Department of Energy and Climate Change, London, UK (2007).

BP. BP Statistical Review of World Energy. BP, London, UK (2011).

43 BP. Energy Outlook 2030. BP, London, UK (2012).

44 Financial Post. Australia says shale could double its gas resources. Financial Post, 14 May (2012).
45 Junginger M, Bolkesjo T, Bradley D et al Developments in international bioenergy trade. Biomass Bioenergy 32(8), 717-729 (2008).

46 Smeets E, Faaij A, Lewandowski I. A Quickscan of Global Bio-Energy Potentials to 2050 - An Analysis of the Regional Availability of Biomass Resources for Export in Relation to the Underlying Factors. Copernicus Institute, Utrecht, The Netherlands (2004).

47 Paltsev S. Russia's Natural Gas Export Potential up to 2050. Massachusetts Institute of Technology, MA, USA (2011).

48 International Atomic Energy Agency. Regulations for the Safe Transport of Radioactive Material. IAEA Safety Standards Series No. TS-R-1. International Atomic Energy Agency, Vienna, Austria (2005).

49 Carola Hoyos and Guychazan. UK warned over dependence on Qatar gas. Financial Times, 15 January (2012).

50 Kavalov B, Petric H, Georgakaki A. Liquefied Natural Gas for Europe - Some Important Issues for Consideration. EC, Office for Official Publications of the European Communities, Luxembourg (2009).

51 Bradley D, Diesenreiter F, Wild M, Tromborg E. World Biofuel Maritime Shipping Study. IEA Bioenergy, Paris, France (2009).

\section{- Websites}

101 Sea Distances - voyage calculator. www.sea-distances.com (Accessed 17 July 2012)

102 Department of Energy and Climate Change. 2050 pathways calculator. http://2050-calculator-tool.decc.gov.uk/ pathways/primary_energy_chart (Accessed 31 May 2012) 